\title{
Physical and chemical characterization of masa and tortillas from parental lines, crosses, and one hybrid**
}

\author{
C. Valderrama-Bravo 1,2,3*, A. Domínguez-Pacheco ${ }^{3}$, C. Hernández-Aguilar ${ }^{3}$, R. Zepeda-Bautista ${ }^{3}$, \\ A. del Real-López $z^{4}$ M.E. Pahua-Ramos ${ }^{5}$, J.L. Arellano-Vázquez ${ }^{6}$, and E. Moreno-Martínez \\ ${ }^{1}$ Department of Engineering and Technology LEM-I (Laboratory Experimental Multidisciplinary-Food Engineering), \\ Faculty of Studies Cuautitlan Superiors, UNAM, Campus 1, First of May, Infonavit Centro, Cuautitlán Izcalli, \\ State of Mexico C.P. 54725, Mexico \\ ${ }^{2}$ Department of Mathematics, Faculty of Studies Cuautitlan Superiors, UNAM, Campus 4, Km. 2.5 Highway Cuautitlán-Teoloyucan \\ San Sebastián Xhala, Cuautitlán Izcalli, State of Mexico, C. P. 54725, Mexico \\ ${ }^{3}$ National Politecnic Institute, Postgraduate and Research Section, ESIME, Professional Unit 'Adolfo López Mateos', \\ Col. Lindavista, Mexico City, C.P. 07738, Mexico \\ ${ }^{4}$ Department of Materials Engineering CFATA, UNAM, Campus Juriquilla, Querétaro, Mexico \\ ${ }^{5}$ Department of Chemical Science, Faculty of Studies Cuautitlan Superiors, UNAM, Campus 1, First of May, Infonavit Centro, \\ Cuautitlán Izcalli, State of Mexico, C.P. 54725, Mexico \\ ${ }^{6}$ National Institute for Forestry, Agriculture and Livestock, Experimental Valley of Mexico, km. 13.5 Highway Los Reyes-Texcoco, \\ Coatlinchan, Texcoco, State of Mexico, C. P. 56250, Mexico \\ ${ }^{7}$ Research Unit in Grains and Seeds (UNIGRAS), Faculty of Studies Cuautitlan Superiors, UNAM. Dr. Jorge Jiménez Cantú s/n, \\ Atlamica, Cuautitlán Izcalli, State of Mexico, C.P. 54729, Mexico
}

Received March 23, 2016; accepted November 30, 2016

A b s t r a c t. In maize plant breeding aimed at producing a hybrid, it is necessary to characterize the parents and hybrids by their agronomic aspects and grain quality so that the processing industry may offer consumers a quality product and also improve its efficiency. This study evaluated the viscoelastic parameters of masa and the chemical and texture properties of tortillas obtained from parent lines (M-54, M55, and CML-242), two single crosses (M54xM55 and M55xM54), and one hybrid (H-70). The morphology of the maize grains and tortillas was analyzed using scanning electron microscopy. The firmness of masa obtained from CML-242 and H-70 maize was higher than that from the other maize genotypes. M-54 tortillas showed the lowest crude fiber content. Otherwise, tortillas obtained from the M55xM54 hard grain had the lowest fat content and extensibility, while H-70 tortillas showed an intermediate breaking point and extensibility. M-54 and M54xM55 tortillas were softer due to their more swollen starch granules. In contrast, rigid tortillas were obtained from CML-242 and H-70. Grain hardness causes different morphology in starch and tortilla of maize genotypes. However, grain hardness did not influence the characteristics of texture in tortillas.

$\mathrm{K}$ e y w o r d s: masa, tortilla, parental lines, maize hybrid, extensibility

*Corresponding author e-mail: carmenvalde@yahoo.com.mx

**This work was supported by the Research Unit in Grains and Seeds (UNIGRAS), Laboratory Experimental MultidisciplinaryFood Engineering (LEM I) of the Faculty of Studies Cuautitlan Superiors-UNAM, and the research project 'Mathematical models applied to products and wastes of the nixtamalization', No. PIAPIC25 (2014-2015).

\section{INTRODUCTION}

Maize (Zea mays L.) is one of the most extensively cultivated cereal grain crops in the world and represents a crucial source of food, feed, fuel, and fibers (Tenaillon and Charcosset, 2011). This grain represents about 15-56\% of the daily calories in the diets of people in approximately 25 developing countries, particularly in Africa and Latin America. Maize is generally used for the production of flour, tortillas, snacks, steamed products, and breakfast cereals (Rooney and Serna-Saldivar, 2003). In Mexico, maize tortillas are considered the most important food for the population; in 2013, tortilla consumption was 7.4 million $t$, which required about 5 million $t$ of maize grain that represent $17.3 \%$ of the total maize (28.9 million $t)$ used for human alimentation, in the starch industry, for livestock, and as seed to plant etc. (CDRRSSA, 2014). In 2014, Mexico only produced 23.27 million $t$ of maize (SIAP, 2014), which was insufficient to meet the demand for corn; imported maize was used to make up the difference.

Maize tortillas represent the main source of calories and protein; however, the quality of maize proteins is poor because they are deficient in the essential amino acids

(C) 2017 Institute of Agrophysics, Polish Academy of Sciences 
eg lysine and tryptophan (Reyes-Moreno et al., 2013). The chemical composition and physical characteristics of maize determine the quality of the tortilla and nixtamalized maize flour, which is important for the nixtamalization industry (Zepeda et al., 2007). Salinas et al. (1992) evaluated the physical and chemical characteristics of hybrids grown in Valles Altos, among which they identified hybrids of hard and soft endosperm with different characteristics. VázquezCarrillo et al. (2015) mentioned that the physicochemical, rheological, and textural properties of the masa and the quality of the tortillas depend on the maize type and conditions of the nixtamalization process. Tortillas processed from maize hybrids with high oil content have a softer texture and greater elongation (Vázquez-Carrillo et al., 2014).

Due to the economic importance of maize, technology has been used to improve the crop, resulting in genotypes with better agronomic, nutritional, and nutraceutical characteristics. In Mexico, researchers at the International Maize and Wheat Improvement Center (CIMMyT) and the National Research Institute for Forestry, Agriculture, and Livestock (INIFAP) have participated in the production of maize varieties that are adapted to different regions of the country (Virgen-Vargas et al., 2014). Valles Altos has also developed genetically improved maize, which has allowed hybrid generation with high yields and characteristics required for the preparation of tortillas and nixtamalized corn products (Zepeda-Bautista et al., 2009). It is necessary to generate information regarding the physical and chemical characteristics of maize hybrids and their progenitors, parental simple crosses, and inbred lines because some components, such as starch in each maize genotype, directly influence the textural and rheological properties, volume, moisture, and shelf-life of masa and tortillas (Raeker et al., 1998). In addition, consumers and producers of maize prefer varieties that present technological and economic advantages for their processes and products. In a maize plant used for breeding to produce hybrids, it is necessary to characterize the parents (lines and single crosses) and hybrids by their agronomic aspects and grain quality for the processing industry to offer consumers a quality product and improve the efficiency of plant breeding. There is little information in relation to the characteristics of maize grain, which could affect tortilla quality. Therefore, the objective of this research was to evaluate the physical, chemical, and rheological characteristics of nixtamalized masa and tortillas made with white grain of parent lines, single crosses, and one hybrid.

\section{MATERIALS AND METHODS}

In the experimental station of Chapingo Autonomous University, Chapingo, State of Mexico, Mexico, during the spring-summer agricultural cycle of 2013, six genotypes of white maize were sown: three inbred lines (M-54, M55, and CML-242), two simple crosses (M54xM55 and
M55xM54), and one hybrid H-70 (crosses of M54xM55 and CML-242). The genotypes are parents of hybrid H-70; the two single crosses were evaluated because in the seed production of hybrid $\mathrm{H}-70$ it is used as a female parent of the directly or reciprocal single cross (Arellano et al., 2011).

Seeds were sown by hand in dry soil on May 3 at a population density of $62,500 \mathrm{ha}^{-1}$. To fertilize, we used the formula 150-70-30 (NPK). Weeds were controlled by applying a preemergence $1.51 \mathrm{ha}^{-1}$ dose of Primagran gold ${ }^{\circledR}$ (a. i. Atrazina + S-metolaclor), and in a postemergence treatment, when the weeds were $5 \mathrm{~cm}$ in height, $2.01 \mathrm{ha}^{-1}$ of Marvel $^{\circledR}$ (a. i. Dicamba + Atrazina). On November 20 (6.7 months after sowing), the harvest was carried out by hand when the formation of a black layer was observed, which indicated physiological maturity. The drying process was carried out at ambient temperature in the shade (average $14.7^{\circ} \mathrm{C}$ ) for one month. The genotypes of white maize were generated by the National Research Institute for Forestry Agriculture and Livestock (INIFAP).

$\mathrm{Cob}$ and maize grains were measured with a digital caliper TRUPER (model CALDI-6MP, Mexico). Ten samples of each maize genotype cob were measured in length and diameter. Afterwards, the grains were cleaned by removing foreign material, impurities, and broken grains. Twenty clean grains were measured (length, diameter, and thickness), and the geometric mean diameter ( $D g$ ) was calculated using Eq. (1), according to Vilche et al. (2003):

$$
D g=\sqrt[3]{l d t},
$$

$D g$ - geometric mean diameter (mm), $l$ - length $(\mathrm{mm}), d-$ diameter $(\mathrm{mm}), \mathrm{t}$ - thickness $(\mathrm{mm})$.

The hectoliter weight and flotation index were evaluated using the AACC method (2000) and the methodology of Salinas et al. (1992), respectively. The moisture and weight of 100 grains were determined using the procedure described by Serna-Saldivar et al. (1992).

The samples were prepared by cooking $\left(90^{\circ} \mathrm{C}\right) 500 \mathrm{~g}$ of maize in a solution of $1500 \mathrm{ml}$ of water and $5 \mathrm{~g}$ of foodgrade calcium hydroxide (Fermont, Monterrey, Mexico). The cooking time for each genotype depends of grain hardness and it was established in relation to the flotation index, according to NMFX-FF-034/1-SCFI-2002 (SAGARPA; 2002); the steeping time was $12 \mathrm{~h}$. The cooking water (nejayote) was separated, and the nixtamalized samples were washed with $750 \mathrm{ml}$ of water and then milled in a manual mill (Nixtamatic, State of Mexico, Mexico). Then, water was added until the samples reached $52 \%$ moisture to obtain the masa. The masa yield was calculated using Eq. (2):

$$
\text { Yield }=\left(\frac{\text { masa weight }- \text { maize weight }}{\text { maize weigh }}\right) 100 .
$$


Masa discs were shaped using a manual maize tortilla machine. The dimensions of the discs were as follows: diameter, $10.9 \mathrm{~cm}$; thickness, $1.3 \mathrm{~mm}$; and weight, $20 \mathrm{~g}$. These were cooked on 'comal' $\left(220^{\circ} \mathrm{C}\right)$ for $30 \mathrm{~s}$ then turned over and cooked for another $30 \mathrm{~s}$. To complete the cooking phase, the tortillas were turned over once more to the original side until they formed ampoules.

The viscoelastic properties of the masa were measured by running oscillatory tests in a TA Instruments Rheometer (model RT 20 Haake, New Castle, USA). The methodology of Valderrama-Bravo et al. (2015) was also applied. The storage (elastic) modulus $\left(\mathrm{G}^{\prime}\right)$, loss (or viscous) modulus $\left(\mathrm{G}^{\prime \prime}\right)$, and the loss tangent or $\tan \delta\left(\mathrm{G}^{\prime \prime} / \mathrm{G}^{\prime}\right)$ were evaluated using the accompanying software during a frequency sweep $(f)$, which increased from 0.1 to $10 \mathrm{~Hz}$.

Moisture content, ash, protein ( $\mathrm{N} \times 5.85$ ), and fat were evaluated according to AACC methods 44-15, 08-01, 46-13, and 30-25, respectively (AACC, 2000).

The breaking point and extensibility distance of tortilla were measured with a texturometer SHIMADZU (model EZ-S, Tokyo, Japan). The tortilla was placed between two metal plates with an orifice $5 \mathrm{~cm}$ in diameter. An accessory with a spherical tip (diameter $6.25 \mathrm{~mm}$ ) was passed through this orifice at a speed of $1 \mathrm{~mm} \mathrm{~s}^{-1}$. The sphere made contact with the tortilla, which was elongated until it broke. The breaking is the maximum breaking point. The distance after which the spherical tip makes contact with the tortilla and before it breaks is called elongation.

The maize genotype morphology was analyzed using a high vacuum scanning electron microscope (JEOL JSMGOGOLV, Tokyo, Japan). The maize samples were cut in half, and the tortillas were dried until their moisture content

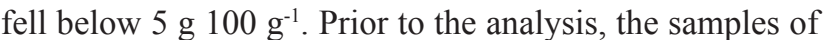
maize and dried tortilla were fixed on a bronze specimen holder with a carbon tape. The samples were covered with gold. The analysis conditions used were $20 \mathrm{kV}$ electron acceleration voltages in the specimen chamber.

Minitab ${ }^{\circledR}$ Statistical software version 15 (Minitab Inc., State College PA, USA) was used to analyze the data by applying an analysis of variance (ANOVA) at a probability of $p<0.05$; significant differences among means were defined using the Tukey test. All the measurements were carried out in triplicate.

\section{RESULTS AND DISCUSSION}

Statistical results showed a significant difference $(p \leq 0.05)$ between parental lines and hybrids in terms of physical characteristics (Fig. 1). Figure 1a and b show the diameter and length of the cob, respectively. Maize cob CML-242 has a smaller size because this inbred line undergoes an average of six to eight self-pollinations; otherwise, cobs H-70 and M55xM54 are larger because the hybrid vigor is expressed. Cobs M-55 and M54xM55 do not exhibit a significant difference in the diameter and length.
Figure 1c shows the $D g$ of the maize grains. H-70 and M55xM54 grains displayed a more significant difference in Dg than CML-242, M54 and M54xM55. Also in Fig. 1c, it can be observed that CML-242 was the smallest grain; however, among M54xM55, M54, and CML-242 grains, no significant difference was observed. Maize genotypes

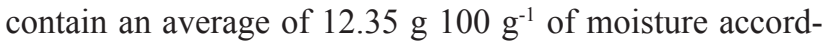
ing to NMFX-FF-034/1-SCFI-2002, which established

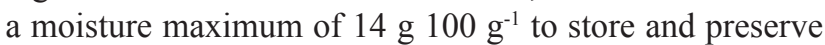
the maize.

The maize genotypes showed a significant difference $(p \leq 0.05)$ in their flotation index, hectoliter weight, and weight of 100 grains (Fig. 1d, e, f, respectively). Grain hardness is a quality parameter of the maize used in nixtamalization, which is evaluated indirectly with hectoliter weight and flotation index (Salinas et al., 1992). The flota-

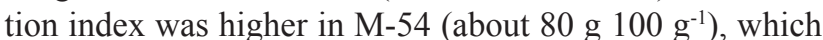
designates a soft grain, while maize hybrid $\mathrm{H}-70$ had the

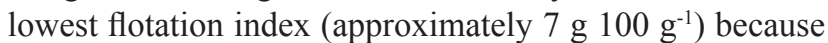
this grain is very hard. On the other hand, maize M-55 and M54xM55 have intermediate hardness because they have a (Fig. 1d) flotation index between $38-40 \%$, while the inbred line CML-242 is classified as a hard grain according to NMFX-FF-034/1-SCFI-2002 (SAGARPA, 2002). Therefore, the cooking times of maize were established in relation to the results of the flotation index as follows: $35,40,30,35,45$, and 40 min for M55, CML-242, M-54, M54xM55, H-70, and M55xM54, respectively. The hectoliter weight of M-54 was the lowest (about $73 \mathrm{~kg} \mathrm{hl}^{-1}$ ), while the other types of maize had hectoliter weights ranging from 74-79 $\mathrm{kg} \mathrm{hl}^{-1}$. Mexican Official Standard NMX-FF-024/1-SCFI-2002 (SAGARPA, 2002) establishes a hectoliter weight minimum of $74 \mathrm{~kg} \mathrm{hl}^{-1}$ and a flotation

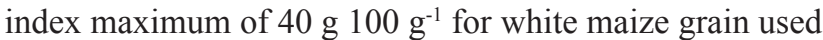
to process tortillas. Vázquez-Carrillo et al. (2011) reported the nixtamalized flour industry demands maize with a flotation index $<40 \%$, while the masa and tortilla industries require grains of soft or intermediate hardness (flotation index $>40 \%$ ). Therefore, inbred lines M-55 and CML-242, parental single crosses of the hybrid H-70, and H-70 could be used in the nixtamalized flour industry, while inbred line M-54 is ideal for the tortilla and masa industries. Therefore, if the parents of the hybrid (lines and single crosses) are of sufficiently good quality for tortillas and masa, it is likely that the hybrid will also meet the quality parameters. The weight of 100 grains was lower for M-55, which is not linked with the size of the grain because it is larger than CML-242. However, M-55 presented a lower hectoliter weight than CML-242, which could be related to the grain porosity or its chemical composition.

Table 1 shows that the masa yield was higher than $50 \%$. The obtained results indicate a higher masa yield of maize genotypes M-55xM-54 and M-55, which are grains with starch granules of intermediate hardness (semi-hard). The hardness of the endosperm determines the speed of 
a
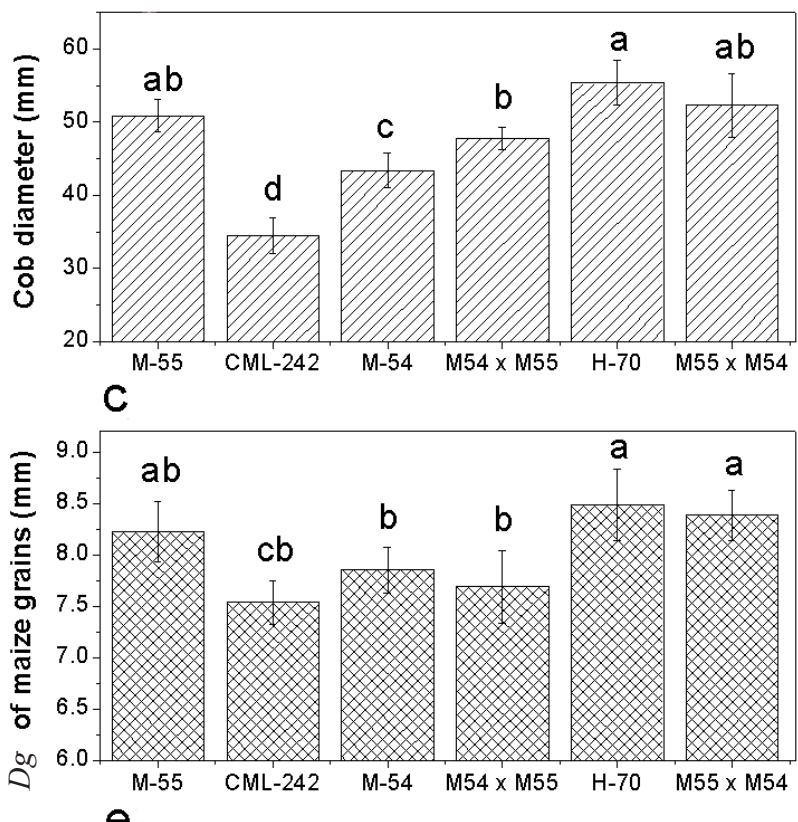

e

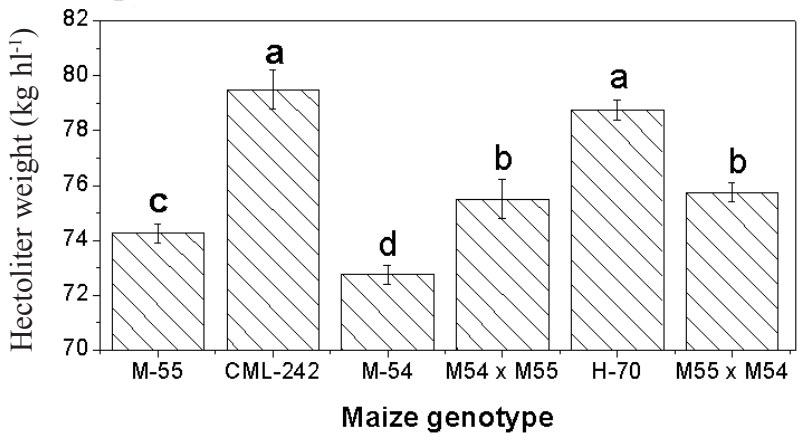

b
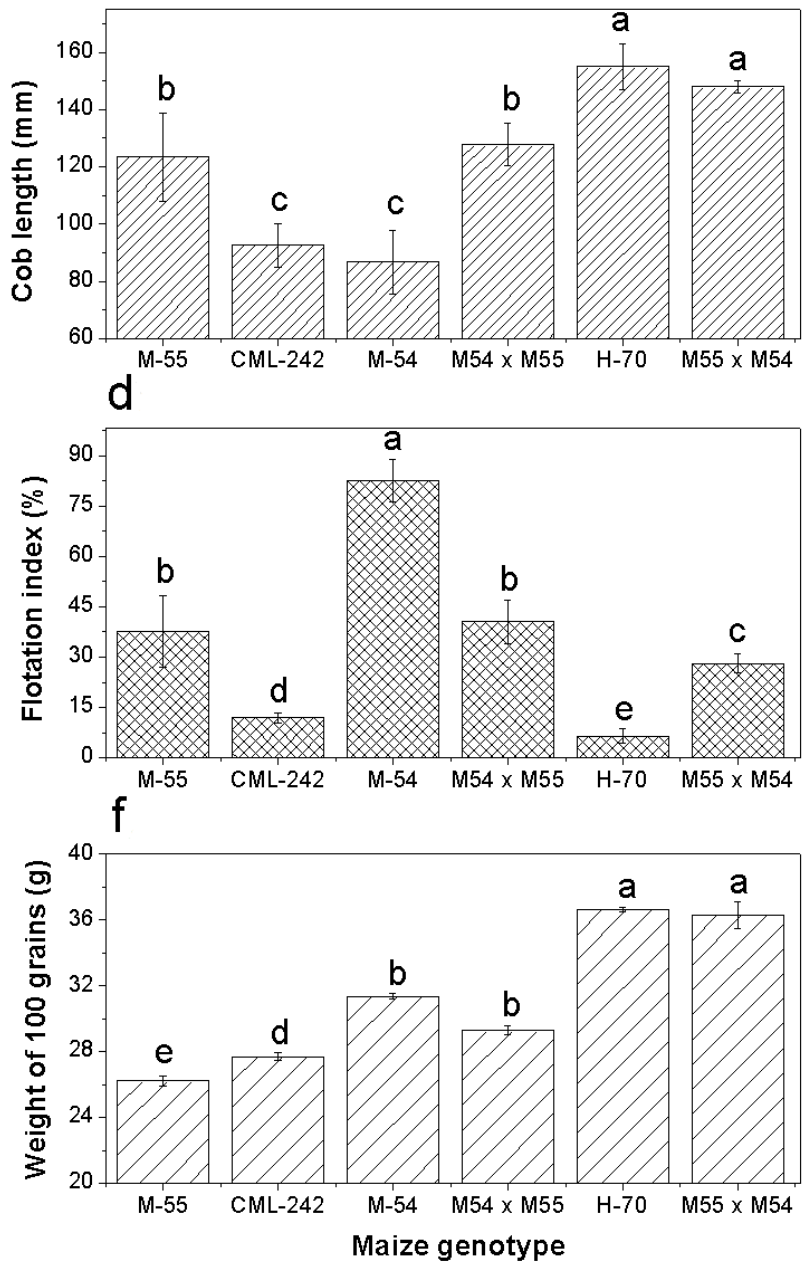

Fig. 1. Physical characteristics of six maize genotypes: $\mathrm{a}-\mathrm{cob}$ diameter, $\mathrm{b}-\mathrm{cob}$ length, $\mathrm{c}-D g$ of maize grains, $\mathrm{d}-$ flotation index, $\mathrm{e}$ - hectoliter weight, and $\mathrm{f}$ - weight of 100 grains.

T a b l e 1. Masa yield from parent lines (M-54, M55, and CML242), two single crosses (M54xM55 and M55xM54), and one hybrid (H-70), Mexico State, Mexico (2013)

\begin{tabular}{cc}
\hline Maize genotype & Masa yield (\%) \\
M54 & $53.97 \mathrm{c}$ \\
M55 & $57.81 \mathrm{~b}$ \\
CML-242 & $54.54 \mathrm{c}$ \\
M54 x M55 & $55.64 \mathrm{c}$ \\
M55 x M54 & $62.88 \mathrm{a}$ \\
H-70 & $54.32 \mathrm{c}$ \\
\hline
\end{tabular}

Mean \pm standard deviation values followed of different letter in each row, are significantly different $(\mathrm{p}<0.05)$. water penetration into the grain during cooking (AlmeidaDomínguez et al., 1996). Grains with a hard endosperm possess starch granules grouped into a protein network that avoids water absorption. On the other hand, in grains with a soft endosperm, the water absorption capacity increases, which contributes to a higher masa yield (Mauricio et al., 2004). Serna-Saldivar et al. (1992) mentioned that the optimum maize to nixtamalizate could have a semi-hard to hard endosperm, since this results in lower loss of the dry matter during the nixtamalization process.

Figure 2 shows the storage modulus $\left(\mathrm{G}^{\prime}\right)$ and the loss modulus $\left(G^{\prime \prime}\right)$ of masa obtained from the inbred lines, single crosses, and hybrids of maize. Filled symbols correspond to $G^{\prime}$ and empty symbols to $G^{\prime \prime}$. If $G^{\prime}>G^{\prime \prime}(\tan \delta<1)$, the material is considered predominantly a gel or solid. On the other hand, when $G^{\prime}<G^{\prime \prime}(\tan \delta>1)$, the material tends toward liquid behaviour. It is noteworthy that in all masas from the maize genotypes, $G^{\prime}$ values predominated over $\mathrm{G}^{\prime \prime}$ values, and therefore, masa is considered predominantly a gel or solid, because the masa compounds form 


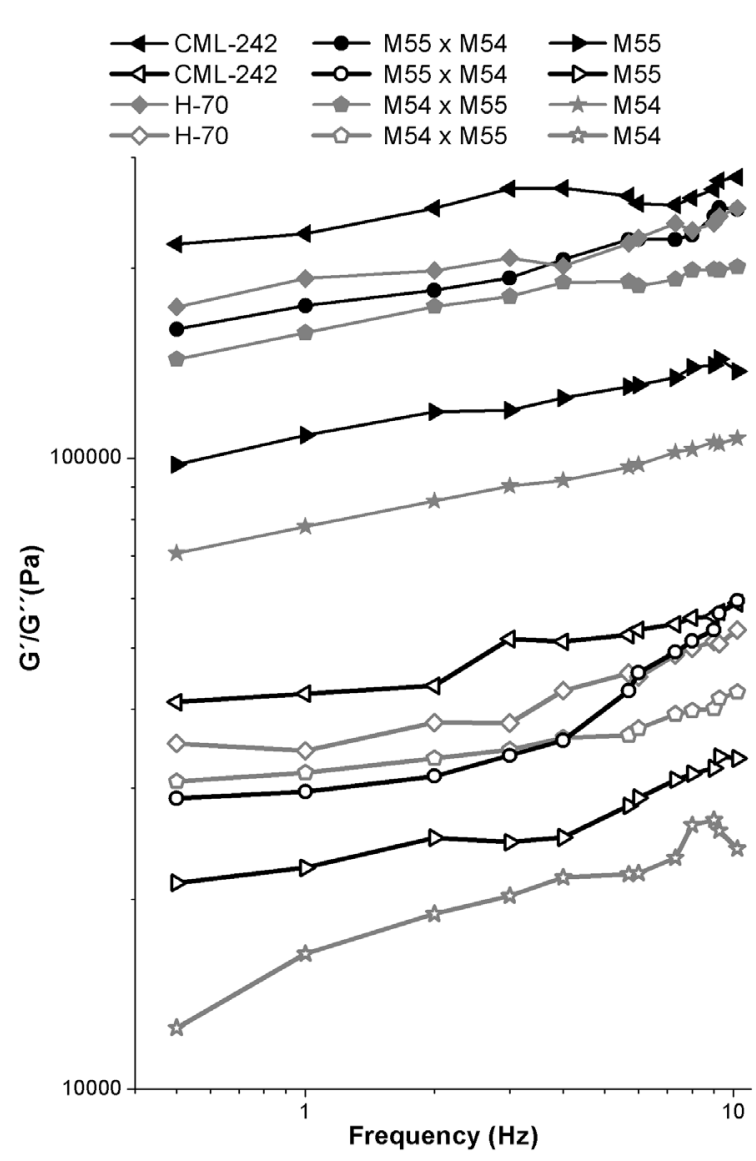

Fig. 2. Viscoelastic properties of masa obtained from six maize genotypes. Filled symbols correspond to $\mathrm{G}^{\prime}$ and empty symbols to $\mathrm{G}^{\prime \prime}$.

a network containing more agglomerated compounds, which cause less molecular mobility, yielding a structure with more elastic behaviour. This fact supports the behaviour of weak gels in masa (Valderrama-Bravo et al., 2015).

Inbred lines CML-242 and M-54 show higher and lower $G^{\prime}$ and $G^{\prime \prime}$ values, respectively, while H-70 shows higher modules $G^{\prime}$ and $G^{\prime \prime}$ than those in crosses M55xM54 and M54xM55 and inbred line M-55.

The range of $\tan \delta$ values for maize genotypes M54 x M55 (0.25-0.26), M-55 (0.23-0.25), and M54 (0.20-0.25) were higher than those in maize genotypes M55 x M54 (0.19-0.24), CML-242 (0.18-0.21), and H-70 (0.18-0.20). Tan $\delta$ values show that masas tend toward behaviours characteristic of elastic solid material; because the values are lower than unity, they behave as weak viscoelastic gels with an amorphous structure (Quintanar et al., 2009).

These results show that the masa viscoelasticity from CML-242 and H-70 was higher than that obtained from the other genotypes, whose masa is firmer. This behaviour can be attributed to grain hardness because CML-242 and H-70 showed a lower flotation index (Fig. 1d, e) and higher cooking times than the other genotypes. On the other hand, masa viscoelasticity can change by interactions among its compounds. The endosperms of the maize genotypes are also different, ie a vitreous endosperm predominates in hard grains and a floury endosperm is dominant in soft grains, and the amylose/amylopectin relations between these endosperms are different. Therefore, the biosynthesis mechanisms of starch are different in all maize genotypes. According to Mondragón et al. (2006), the formation of amylose-lipid complexes can cause viscoelasticity reduction in the masa.

Consequently, no association forms between chains, resulting in a softer masa. Quintanar et al. (2009) also reported that the differences in $\mathrm{G}^{\prime}$ and $\mathrm{G}^{\prime \prime}$ could be attributed to probable interactions between starch and other maize components, such as proteins and lipids that cause stiffness in the masa.

The protein content of tortillas obtained from a parental single cross of hybrid H-70 M54xM55 and inbred line CML-242 was higher than that seen in genotypes M54, M55, M55xM54, and H-70. However, all tortillas contained high levels of protein (10.73-12.44 g $\left.100 \mathrm{~g}^{-1}\right)$. These results are in accordance with the findings of Vázquez-Carrillo et al. (2011) (Fig. 3a), who determined the protein content in tortillas processed from landraces maize (9.76-12.54 g

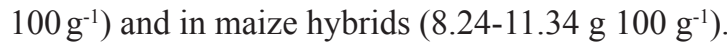

The fat content showed (Fig. 3b) a significant difference $(p<0.05)$ among all tortillas processed from the different genotypes. Tortillas with the lowest fat content were obtained from genotypes M55xM54 and H-70, which were hard and very hard grains, respectively. Among tortillas from maize genotypes M54xM55, M-54, CML-242, and $\mathrm{M}-55$, there was no significant difference in the fat

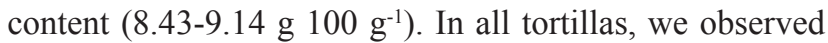
higher levels of fat content than in the tortillas evaluated by Vázquez-Carrillo et al. (2014), which were processed

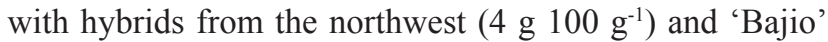

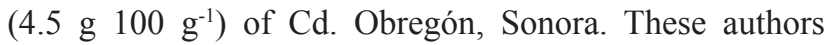
mentioned that the oil losses that occur during the nixtamalization process can be attributed to lipid hydrolysis in an alkaline solution that promotes lipid solubilization in the nejayote. The maize genotypes analyzed in this study had low losses of oil during nixtamalization. The tor-

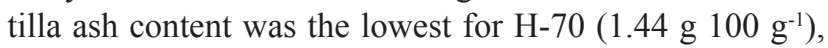
while the highest levels were $1.83,1.84$, and $1.86{\mathrm{~g} 100 \mathrm{~g}^{-1}}^{-1}$ for CML-242, M54xM55, and M-55, respectively. These results were similar to those of Grajales-García et al. (2012) for tortillas from quality protein maize (QPM) and

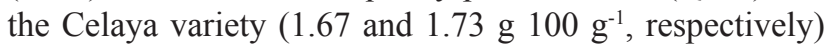
(Bello-Perez et al., 2014).

Statistical analyses showed a significant difference $(p<0.05)$ in the crude fibre content among all tortillas obtained from the inbred lines, single crosses, and hybrid maize types. Tortillas made with the M-54 maize grain had the lowest level of crude fibre $\left(2.94 \mathrm{~g} 100 \mathrm{~g}^{-1}\right)$. This result was similar to the findings of Pappa (Palacios and

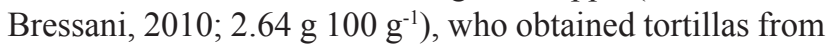


white maize grown in Guatemala. In contrast, M-55 tortillas showed the highest crude fibre content $\left(6.94{\left.\mathrm{~g} 100 \mathrm{~g}^{-1}\right)}^{-1}\right.$ because the pericarp is not removed in full during nixtamalizacion. This behaviour was observed by Zepeda-Bautista et al. (2009) when evaluating single crosses of MT-2223 and MT-1415. This is very important nutritionally because tortilla consumption has been associated with overweight and obesity (Rodríguez-Ramirez et al., 2011). Thus, tor-

T a b l e 2. Breaking point and extensibility distance of fresh tortillas from parent lines (M-54, M55, and CML-242), two single crosses (M54xM55 and M55xM54), and one hybrid (H-70), Mexico State, Mexico (2013)

\begin{tabular}{ccc}
\hline $\begin{array}{c}\text { Maize } \\
\text { genotype }\end{array}$ & $\begin{array}{c}\text { Breaking point } \\
(\mathrm{N})\end{array}$ & $\begin{array}{c}\text { Extensibility } \\
\text { distance }(\mathrm{mm})\end{array}$ \\
\hline M54 & $0.415 \mathrm{c} \pm 0.037$ & $3.238 \mathrm{ab} \pm 0.234$ \\
M55 & $0.628 \mathrm{ab} \pm 0.050$ & $3.636 \mathrm{ab} \pm 0.149$ \\
CML-242 & $0.654 \mathrm{a} \pm 0.061$ & $3.748 \mathrm{a} \pm 0.182$ \\
M54 x M55 & $0.530 \mathrm{~b} \pm 0.049$ & $3.538 \mathrm{ab} \pm 0.389$ \\
M55 x M54 & $0.570 \mathrm{ab} \pm 0.059$ & $3.127 \mathrm{~b} \pm 0.450$ \\
H-70 & $0.608 \mathrm{ab} \pm 0.042$ & $3.259 \mathrm{ab} \pm 0.065$ \\
\hline
\end{tabular}

Explanations as in Table 1.

a

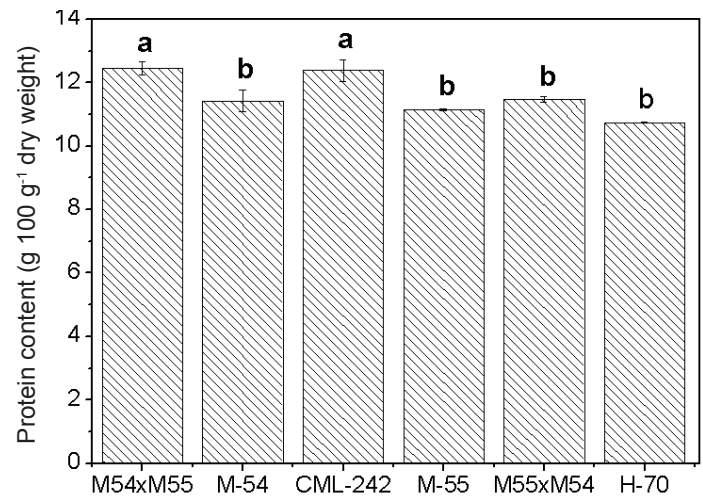

$\mathrm{c}$

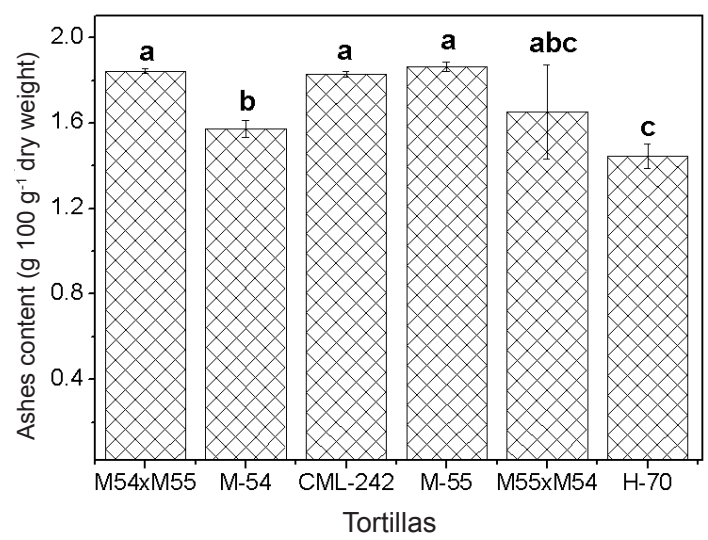

tillas with high fibre content are recommended because of their bulking properties and rapid transit through the stomach and intestines (Bello-Perez et al., 2014).

Table 2 shows the breaking point and extensibility distance results for fresh tortillas obtained from the different maize genotypes. The data indicated the lowest and highest breaking points for M-54 $\left(0.4146^{c} \pm 0.037\right)$ and CML$242\left(0.6541^{\mathrm{a}} \pm 0.061\right)$ tortillas, respectively. However, no significant differences were observed among the tortillas obtained from maize M-55, M55xM54, and H-70 because the inbred line and single cross are the female parents of maize hybrid H-70 (Arellano et al., 2011). Similarly, the extensibility distance did not show a significant difference among the M54xM55, M-54, M-55, and H-70 tortillas. The CML-242 and M55xM54 tortillas had the highest and lowest extensibility, respectively. The breaking point is likely associated with the grain hardness because M-54 is a soft grain, while the CML-242 genotype is a hard grain. In addition, the fat and fibre content of tortillas can also be important influencing factors because the M-54 tortillas had high fat content (Fig. 3b), which produced softer and less extensible tortillas $\left(3.2378^{\mathrm{ab}} \pm 0.234\right)$. In turn, the CML-242 tortillas also had high fat content (Fig. 3b) but were harder and more extensible $\left(3.7481^{\mathrm{a}} \pm 0.182\right)$. These results were in agreement with those of Vázquez-Carrillo et al. (2015). In contrast, tortillas obtained from a semihard grain, such as M55xM54, had the lowest fat content b

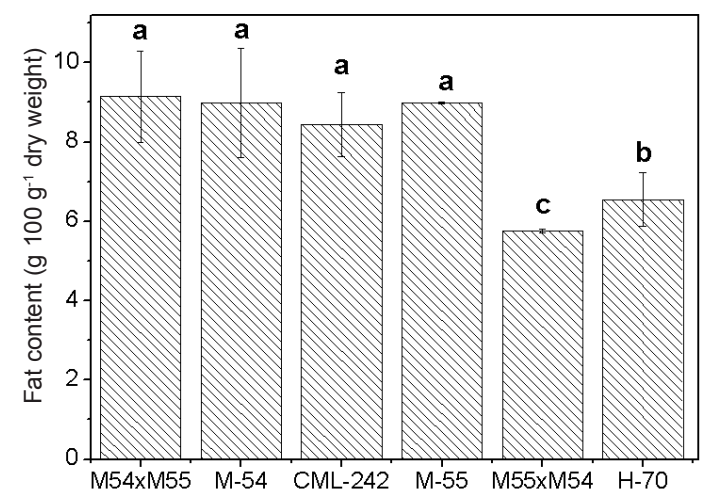

d

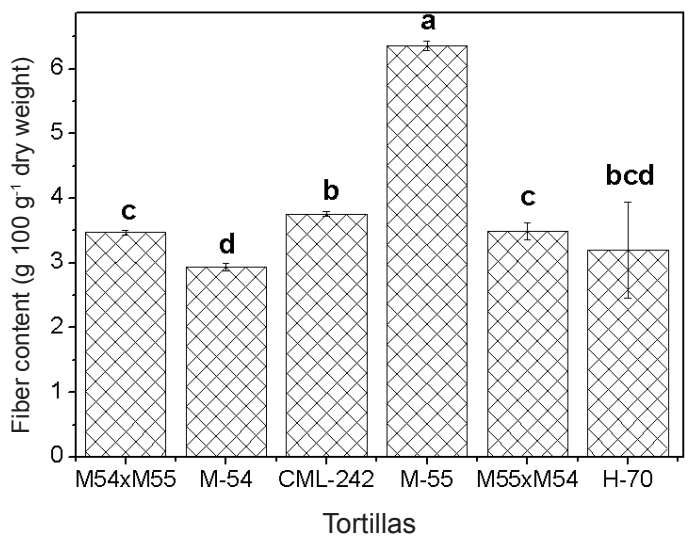

Fig. 3. Chemical properties of tortillas obtained from six maize genotypes: $a$ - protein, $b$ - fat, $c$ - ashes, and d - fibre. 
(Fig. 3b) and extensibility $\left(3.1266^{\mathrm{b}} \pm 0.450\right)$, while the $\mathrm{H}-70$ tortillas made with very hard grains showed an intermediate breaking point $\left(0.6078^{\mathrm{ab}} \pm 0.042\right)$ and extensibility $\left(3.2592^{\mathrm{ab}} \pm 0.065\right)$. Therefore, the hardness of the grain did not affect the tortilla texture characteristics (breaking point and extensibility) (Bello-Perez et al., 2014; SalinasMoreno and Aguilar-Modesto, 2010).

In contrast, M-54 tortillas showed the lowest fibre content (Fig. 3d), which may affect the textural properties because this genotype (M-54) is a very soft grain through which water penetrates, which facilitates elimination of the pericarp but can reduce the amount of natural gums (Martínez-Bustos et al., 2001). Textural changes may also be related to the competition of starch, proteins, and fibre for water, resulting in different degrees of hydration and plasticization of starch in the matrix that forms.

Figure 4 shows scanning electron microscopy (SEM) images of the floury endosperm of three inbred lines of the maize genotypes M-54, M-55, and CML-242 (Fig. 4a, c, e) and their tortillas $(4 \mathrm{~b}, \mathrm{~d}, \mathrm{f})$. The starch granules differ among the maize. Inbred line M-54 has a maize grain with a soft endosperm and starch granules of average size
(10-14 $\mu \mathrm{m})$ with a uniform round form (Fig. 4a). Maize grain M-55 (Fig. 4c) has a semi-hard endosperm and partially round as well as undefined starch granule sizes that are both smaller $(8 \mu \mathrm{m})$ and larger $(16 \mu \mathrm{m})$ than those of M-54. CML-242 (Fig. 4e) maize has a hard endosperm with more packed starch granules. In Figure 4e, the starch granules $(9-15 \mu \mathrm{m})$ have different shapes (round, polyhedral). Tortillas made with the maize grain from inbred line M-54 (Fig. 4b) contain swollen starch granules and a softer texture. Conversely, the M-55 and CML-242 tortillas contain only some swollen starch granules, but their texture is more rigid.

Figure 5 shows SEM images of the floury endosperm of two single crosses of maize M54xM55 and M55xM54 (Fig. 5a, c) and the H-70 maize hybrid (Fig. 5e) and its tortillas $(5 b, d, f)$. The maize grains of the single cross of M54xM55 contain a semi-hard endosperm with starch granules $(9-13 \mu \mathrm{m})$ that have a uniform round form (Fig. 5a). M55xM54 and H-70 produce maize with hard and very hard endosperms, respectively. Figure $5 \mathrm{c}$ and $5 \mathrm{e}$ show starch granules with an irregular polyhedral form and an undefined shape, with a larger size $(12-17 \mu \mathrm{m})$ than
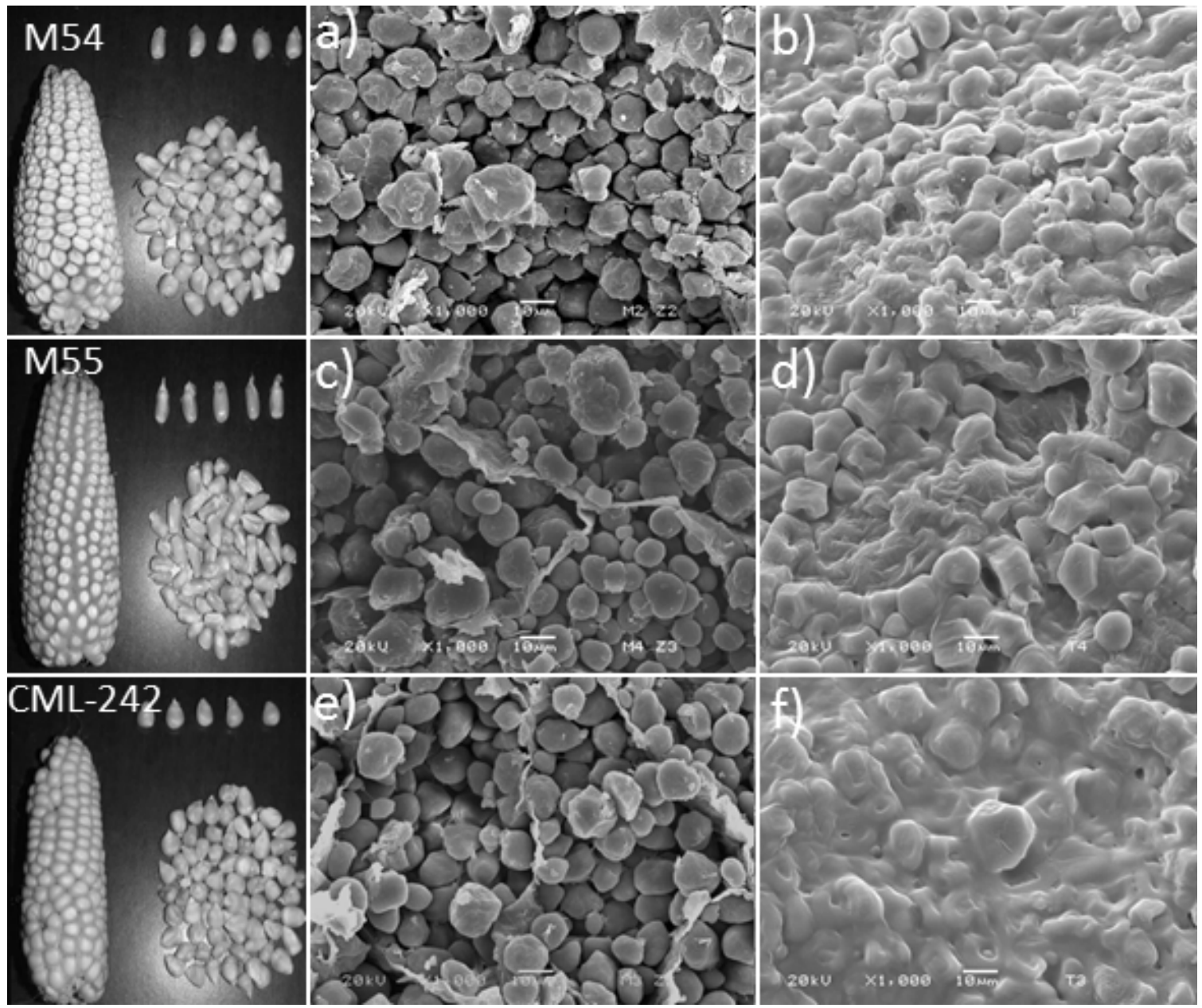

Fig. 4. SEM images 1000x: M-54 a - maize, b - tortilla; M-55 c - maize, d-tortilla; CML-242 e - maize, $\mathrm{f}$ - tortilla. 

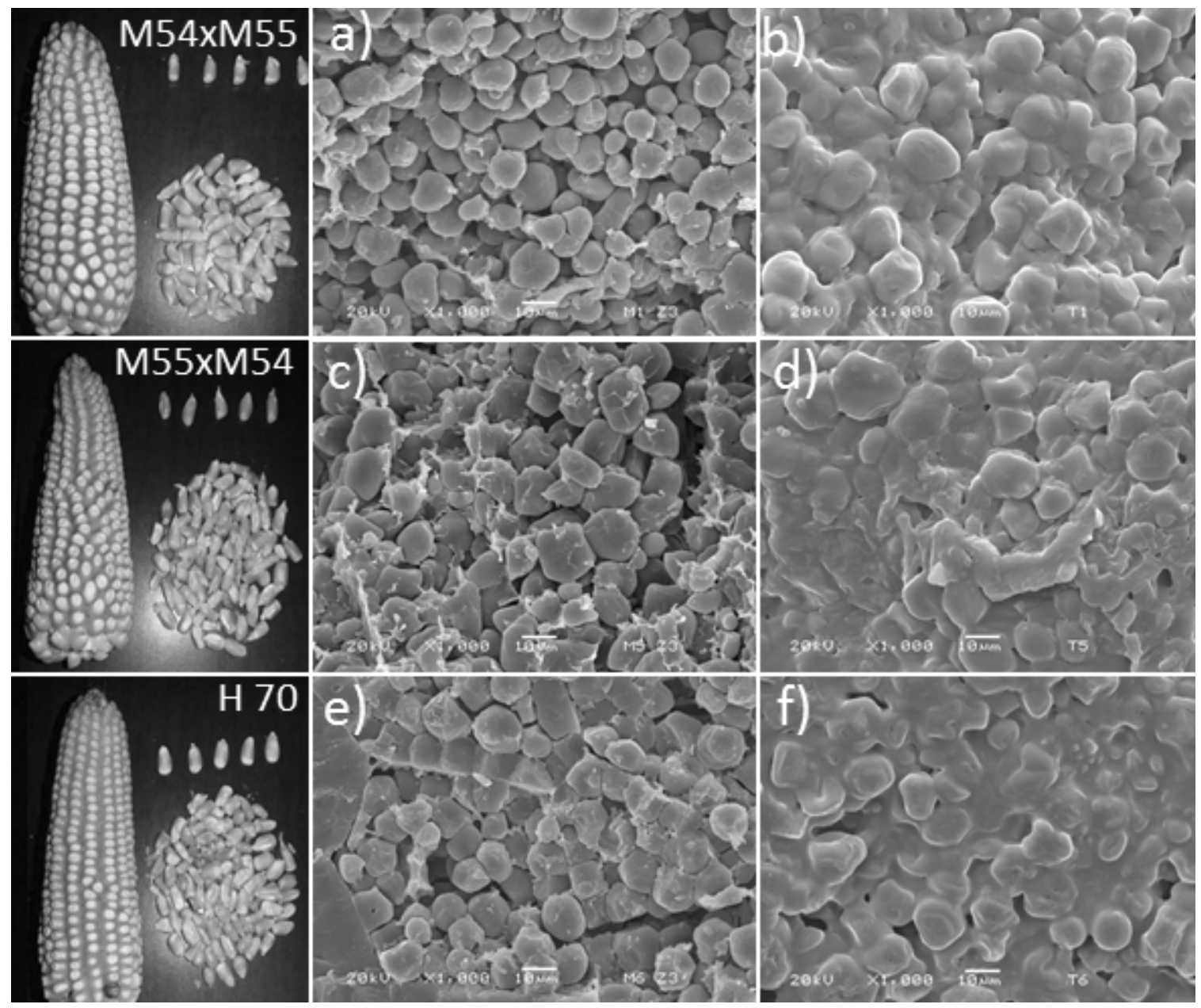

Fig. 5. SEM images 1000x: M54xM55 a - maize, b - tortilla; M55xM54 c - maize, d - tortilla; H-70 e - maize, f - tortilla.

the other genotypes. The starch granules are more closely packed and they have a rough texture. Moreover, these maize grains are larger (Fig. 1c).

Tortillas made with the maize grains of the single cross of M54xM55 (Fig. 5b) show some swollen starch granules and have an adhesive texture. However, in tortillas made with M55xM54 (Fig. 5d) and H-70 (Fig. 5f), no swollen starch was observed. The texture of these tortillas was rigid, which could affect its quality in regard to firmness, rollability, and fracturability. Inbred lines M-54 (soft endosperm) and M-55 as well as single cross M54xM55 (semi-hard endosperm) produced the softest tortillas (Fig. 4b, d, b) with higher swollen starch content. The water absorption in the granules was higher in these grains, which contributed to the gelatinization process. In contrast, CML242 and M55xM54 (hard endosperm) and H-70 (very hard endosperm) produced rigid tortillas (Figs 4f, 5d, f). Grain hardness is therefore an intrinsic physical parameter that depends on both the genetics and the environment (DorseyRedding et al., 1991), which mainly affects the starch type and, consequently, its products according to their breaking point and extensibility (Table 2).

\section{CONCLUSIONS}

1. The physical and chemical characteristics of nixtamalized masa and tortillas made with grain from the parent lines of hybrid $\mathrm{H}-70$ were different because of their genetic constitution, while the hybrid had some similar characteristics that were inherited from the lines.

2. Hybrid H-70 and single cross M55xM54 contain the largest grains, and their starch granules present with a greater size than the other genotypes.

3. The masa viscoelasticity obtained from the CML-242 and H-70 maize was higher than that of the other genotypes, whose masa was firmer. Tortillas of these genotypes showed a rigid texture.

4. Inbred line M-54 is a grain with a soft endosperm, and its starch granules are more uniform in both size and form. Tortillas produced from M-54 contain more swollen starch granules, which could improve their softness. Therefore, the breaking point of M-54 tortillas was lower than that of other tortillas.

5. Maize genotype hybrid H-70 is a grain used during nixtamalization and the two crosses of M55xM54 and M54xM55 showed similar behaviour in viscoelastic and 
chemical properties, breaking point and extensibility distance. Consequently, the two crosses of M55xM54 and M54xM55 are grains that can be processed in nixtamalization industry.

\section{ACKNOWLEDGMENTS}

The authors thank Karina Cruz Zacarias of the Faculty of Studies Cuautitlan Superiors-UNAM for her technical support and the National Research Institute for Forestry Agriculture and Livestock (INIFAP), in Texcoco, State of Mexico, for providing the maize grain lines and hybrids. Valderrama-Bravo C. would also like to thank CONACYTMéxico for the financial support of her post-doctoral position at ESIME-Zacatenco, IPN.

Conflict of interest: The Authors do not declare conflict of interest.

\section{REFERENCES}

AACC, 2000. Approved methods of the American Association of Cereal Chemists. Method 84-10 and 08-01. American Association of Cereal Chemists, St. Paul, MN, USA.

Almeida-Domínguez H.D., Cepeda M., and Rooney L.W., 1996. Properties of commercial nixtamalized corn flours. Cereal Foods World, 41, 624-630.

Arellano-Vázquez J.L., Virgen-Vargas J., Rojas-Martínez I., and Avila-Perches M., 2011. H-70: High yield maize hybrid for rainfed and irrigated of central Highlands of Mexico (in Spanish). Rev. Mex. Cienc. Agríc., 2, 619-626.

Bello-Perez L.A., Flores-Silva P.C., Agama-Acevedo E., Figueroa-Cardenas J.D., Lopez-Valenzuela J.A., and Campanellla O.H., 2014. Effect of the nixtamalization with calcium carbonate on the indigestible carbohydrate content and starch digestibility of corn tortilla. J. Cereal Sci., 60, 421-425.

CDRRSSA, 2014. Study Center for the Sustainable Rural Development and the Food Sovereignty: Consumption, distribution and food production: The case of the complex maize-tortilla (in Spanish). CDRRSSA, 1-1.

Dorsey-Redding C.D., Hurburgh C.R, Johnson L.A., and Fox S.R., 1991. Relationships among corn quality factors. Cereal Chem., 68, 602-605.

Grajales-García E.M., Osorop-Díaz P., Goñi I., HervertHernandez D., Guzman-Maldonado H., and Bello-Pérez L.A., 2012. Chemical composition, starch digestibility and antioxidant capacity of tortilla made with a blend of quality protein maize and black bean. Int. J. Mol. Sci., 13, 286-301.

Martínez-Bustos F., Martínez-Flores H.E., SanmartínMartínez E., Sánchez-Sinencio F., Chang Y.K., BarreraArellano D., and Rios E., 2001. Effect of the components of maize on the quality of masa and tortillas during the traditional nixtamalization process. J. Sci. Food Agr., 81, 1455-1462.

Mauricio S.R.A., Figueroa J.D., Taba S., Reyes M.L., Rincón F., and Mendoza A., 2004. Characterization of maize accessions by grain and tortilla quality traits (in Spanish). Rev. Fitotec. Mex., 27, 213-222.
Mondragón M., Mendoza-Martínez A., Bello-Pérez L.A., and Peña J.L., 2006. Viscoelastic behavior of nixtamalized maize starch gels. Carbohyd. Polym., 65, 314-320.

Pappa M.R., Palacios de Palomo P., and Bressani R., 2010. Effect of lime and wood ash on the nixtamalization of maize and tortilla chemical and nutritional characteristics. Plant. Food. Hum. Nutr., 65, 130-135.

Quintanar G.A., Jaramillo F.M.E., Escobedo M.R., Chel G L., and Solorza F.J., 2009. Changes on the structure, consistency, physicochemical and viscoelastic properties of corn (Zea mays sp.) under different nixtamalization conditions. Carbohyd. Polym., 78, 908-916.

Raeker M.Ö., Gaies C.S., Finey P.L., and Donelson T., 1998. Granule size distribution and chemical composition of starches from 12 soft wheat cultivars. Cereal Chem., 75, 721-728.

Reyes-Moreno C., Ayala-Rodriguez A.E., Milán-Carrillo J., Mora-Rochín S., López-Valenzuela J.A., Valdez-Ortiz A., Paredes-López O., and Gutiérrez-Dorado R., 2013. Production of nixtamalized flour and tortillas from amarantin transgenic maize lime-cooked in a thermoplastic extruder. J. Cereal Sci., 58, 465-471.

Rodríguez-Ramirez S., Mundo-Rosas V., García-Guerra A., and Shamah-Levy T., 2011. Dietary pattern are associated with overweight and obesity in Mexican schoolage children. Archivos Latinoamericanos de Nutrición, 61, 270-278

Rooney L.W. and Serna-Saldivar S.O., 2003. Food use of whole corn and dry-milled fractions. In: Corn: Chemistry and Technology (Eds P.J. White, L.A. Johnson). American Association of Cereal Chemists, St. Paul, MN, USA.

SAGARPA, Secretariat of Agriculture, Livestock, Rural Development, Fisheries and Food, 2002. Norma Mexicana NMXFF-034/1-SCFI-2002. Non industrialized food products for human consumption-Cereals-Part I: White corn for alkaline process of corn tortillas and nixtamalized corn products-specifications and test methods. General Direction of Norms. SAGARPA. Mexico.

Salinas Y., Arellano L.V. and Bustos M., 1992. Comparison of methods for determining corn hardness (Zea mays L.) (in Spanish). Archivo Latinoamericano de Nutrición., 42, 59-63.

Salinas-Moreno Y. and Aguilar-Modesto L., 2010. Effect of maize (Zea mays L.) grain hardness on yield and quality of tortilla (in Spanish). Ingeniería Agricola y Biosistemas, 2, $5-11$.

Serna-Saldivar S.O., Gomez M.H., Islas-Rubio A.R., Bockholt A.J., and Rooney L.W., 1992. The alkaline processing properties of quality protein maize. In: Quality Protein Maize (Ed. E.T. Mertz), AACC Press, St. Paul, MN, USA.

SIAP/SAGARPA, 2014. Information and statistics service agrifood and fisheries (in Spanish). http://www.sagarpa.gob.m.

Tenaillon M.L. and Charcosset A., 2011. A European perspective on maize history. C. R. Biol., 334, 221-228.

Valderrama-Bravo C., López-Ramírez Y., Jiménez-Ambriz S., Oaxaca-Luna A., Domínguez-Pacheco A., HernándezAguilar C., and Moreno-Martínez E., 2015. Changes in chemical, viscoelastic, and textural properties of nixtamalized dough with nejayote. LWT- Food Sci. Technol., 61, 496-502. 
Vázquez-Carrillo G., García-Lara S., Salinas-Moreno Y., Bergynson D.J., and Palacios-Rojas N., 2011. Grain and tortilla quality in landraces and improved maize grown in the Highlands of Mexico. Plant Food. Hum. Nutri., 66, 203-208.

Vázquez-Carrillo M.G., Santiago-Ramos D., Gaytán-Martínez M., Morales-Sánchez E., and Guerrero-Herrera M.J., 2015. High oil content maize: Physical, thermal and rheological properties of grain, masa, and tortillas. LWT- Food Sci. Technol., 60, 156-161.

Vázquez-Carrillo M.G., Santiago-Ramos D., Salinas-Moreno Y., López-Cruz J., Ybarra-Moncada M.C., and OrtegaCorona A., 2014. Oil content in maize (Zea mays L.) genotypes and its relationship with quality and texture of tortilla. Agrociencia, 48, 159-172.

Vilche C., Gely M.C., and Santalla E., 2003. Physical properties of quinoa seeds. Biosyst. Eng., 86, 59-65.
Virgen-Vargas J., Zepeda-Bautista R., Avila-Perches M.A., Espinosa-Calderón A., Arellano-Vázquez J.L., and Gámez-Vázquez A.J., 2014. Seed production lines of maize: population density and interaction (in Spanish). Agron. Mesoam., 25, 323.

Zepeda-Bautista R., Carballo-Carballo A., and HernándezAguilar C., 2009. Genotype environment interation in structure and nixtamal-tortilla. Quality of kernel in maize hybrids. Agrociencia, 43, 695-706.

Zepeda-Bautista R., Carballo-Carballo A., Muñoz Orozco A., Mejía Contreras J.A., Figueroa Sandoval B., and González Cossio F.V., 2007. Nitrogen fertilization effect on the physical structural and alkaline-cooking quality characteristics of grain hybrids (in Spanish). Agric. Téc. Méx., 33, 17-24. 